\title{
ArcheoSciences
}

Revue d'archéométrie

33 (suppl.) | 2009

Mémoire du sol, espace des hommes

\section{What do all the numbers mean? \\ Making sure we have all the pieces of the puzzle}

Thomas Sparrow, Chris Gaffney and Armin Schmidt

\section{(2) OpenEdition}

1 Journals

Electronic version

URL: https://journals.openedition.org/archeosciences/1842

DOI: 10.4000/archeosciences. 1842

ISBN: 978-2-7535-1599-4

ISSN: 2104-3728

Publisher

Presses universitaires de Rennes

Printed version

Date of publication: 30 October 2009

Number of pages: $361-362$

ISBN: 978-2-7535-0943-6

ISSN: $1960-1360$

\section{Electronic reference}

Thomas Sparrow, Chris Gaffney and Armin Schmidt, "What do all the numbers mean?

Making sure we have all the pieces of the puzzle", ArcheoSciences [Online], 33 (suppl.) | 2009, Online since 30 October 2011, connection on 21 September 2021. URL: http://journals.openedition.org/ archeosciences/1842 ; DOI: https://doi.org/10.4000/archeosciences.1842 


\title{
What do all the numbers mean? Making sure we have all the pieces of the puzzle
}

\author{
Thomas Sparrow*, Chris Gaffney* and Armin Schmidt*
}

Key Words: Archiving, Documentation, Metadata, TTGA, file formats

As large-scale geophysical surveys increase, data collected using differing techniques mean that documenting and archiving this resource is increasingly significant. With technological advances in geophysical instrumentation, especially the integration of GPS and multisensor platforms, large landscape surveys are increasingly practical and increasingly data-rich. Whilst only a few years ago only one dataset would have been collected at a site, multiple datasets are frequently collected in one "sweep" using cart and sledgebased platforms and, as data collection moves from traditional gridded data to grid-less, previous metadata become a data set in their own right.

Anecdotal evidence from curators and planning departments indicates that despite the increasing number of practitioners working in archaeological geophysics, the quality of archiving needs to be improved. An Institute for Archaeologists (IfA) Special Interest Group into geophysics was set up in 2008 and has a subcommittee reporting on archiving issues, and is a welcome addition to this topical debate. IfA has already acknowledged the need to train practitioners and via a Workplace Learning Bursary: Archaeological Geophysics: from field to archive, hosted by the University of Bradford hopes to address these gaps. This poster highlights the ongoing work, problems, practices, and possible outcome from the Bursary.

One of the drivers for this Bursary was the recent donation to the University of the Time Team Geophysical Archive (TTGA) by GSB Prospection Ltd. The TTGA, as an archive, has great value for academic research but also will promote geophysics to the wider community. The TTGA consists of all the geophysical data that have been collected by GSB Prospection for a British television series aired on Channel 4. Time Team, which has been running since 1994 and are filming its $17^{\text {th }}$ series this year, it specialises in investigating sites in 3 days. One aim of the Bursary is to increase access to the resulting geophysics data.

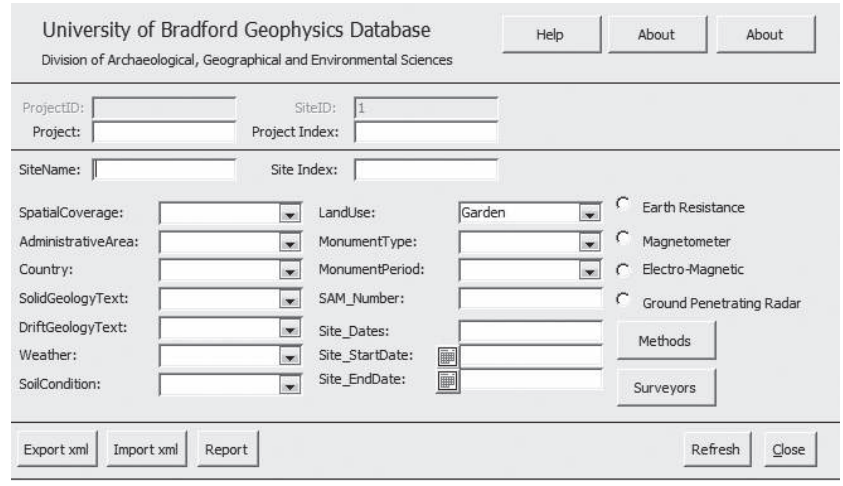

Figure 1: A screen grab of the archival database

The process of collecting high-quality data, reporting and archiving is an increasingly important, but as yet rarely formally taught, aspect of modern geophysical survey. There are few specialists in this area; some academic departments provide only research training whilst few commercial prac-

*Archaeological Sciences, Division of AGES, University of Bradford, U.K. (T.Sparrow1@Bradford.ac.uk) 
titioners have time to accumulate information on best practice for long term archiving. The IfA Workplace Learning Bursary seeks to redress this balance by looking at the 'what's and why's' of current practices by geophysical contractors, the Archaeology Data Service (ADS) and national heritage groups.

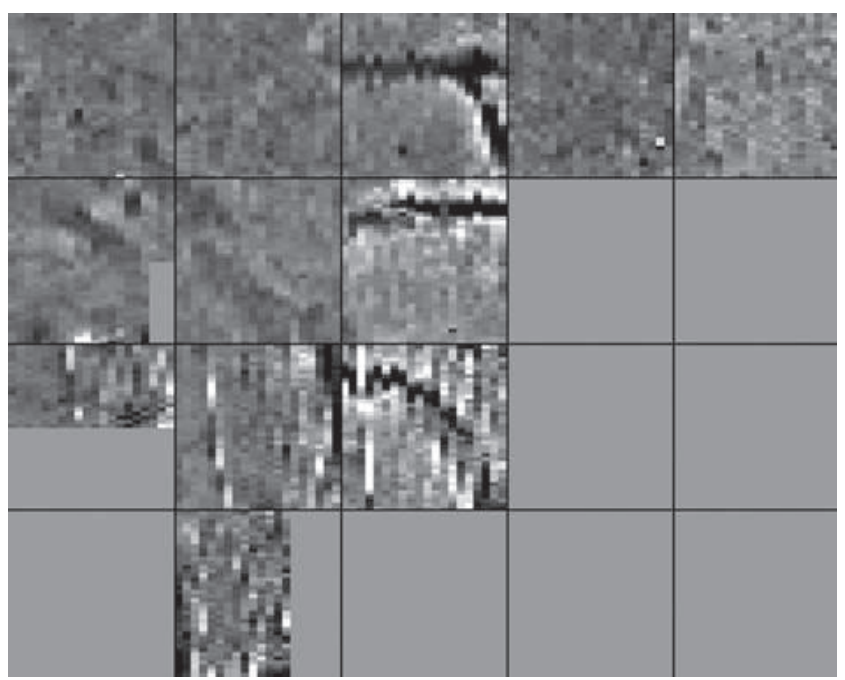

Figure 2a: The lack of the simplest metadata such as grid orientation can to lead basic display problems, above shows an incorrect grid orientation. above shows an Incorrect grid orientation

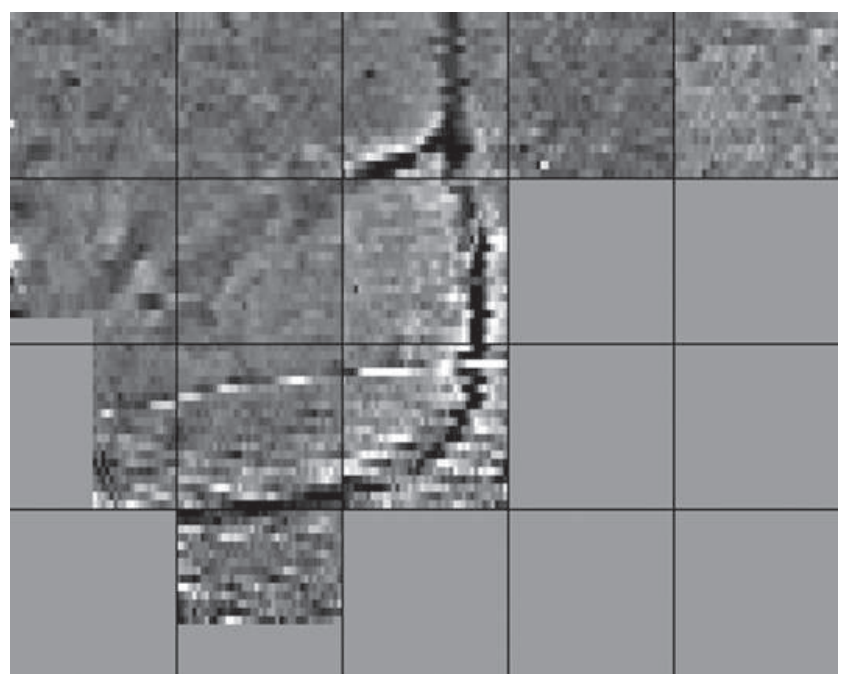

Figure 2b: Above shows the correct grid orientation. There are still errors in the data, but the metadata has allowed the grids to be meshed together in the correct relative locations.

Technical skills are combined with training in data management. This will enable documentation and archiving for archaeological geophysics to become a streamlined practice.
This in turn will lead to more transparent and accessible data that will enable better integration with future geophysical and archaeological research. By developing archival databases and GIS repositories for the TTGA and other University of Bradford geophysical datasets, efficient, effective and useable strategies for archiving are being formulated. Since the beginnings of archaeological geophysics, archiving of resulting data has been an important issue. Over the years many different formats have been produced; these may have the same file extension but vary considerately. Do we know how all our *.DATs , *.XYZs, and *.GRDs fit together?

There is a need to document all the file formats that we use to store and document data. This includes standard proprietary formats as well as in-house formats developed by individual groups.

With the data comes a need for appropriate documentation on how they were collected, and what has happened to them since the initial downloading (Schmidt 2002).

A toolkit is being developed to aid archiving geophysical data. In its final form it will consist of procedures, templates, and software for the documentation, conversion and management of data for extended preservation and use.

To allow access to data for users with different software packages and avoid complications of data migration for subsequent software versions, data are often archived in a very simple and non-proprietary format like "xyz ASCII." However, such discarding of previously accumulated metadata creates problems for later data improvements (e.g. information on grid size, line sequence, uni- or bi-directional). It may hence be necessary to use a well-documented rich archiving format that retains metadata while simultaneously provides simple access to raw or processed measurements. The authors have developed the Archaeological Grid Format (AGF) that may serve this purpose.

A "universal converter" could enable data and metadata to be combined, resulting in fewer files which need to be archived, and converting back into a proprietary format for re-evaluation or reprocessing at a later date. By consolidating the number of different files, it is less likely that a "piece of the puzzle" will be lost.

Without knowing the simplest of metadata, reconstructing simple composite grids can become challenging.

\section{References}

Schmidt, A., 2002. Geophysical Data in Archaeology: A Guide to Good Practice ADS series of Guides to Good Practice. Oxford: Oxbow Books. 